\title{
DISCLAIMER
}

This report was prepared as an account of work sponsored by an agency of the United States Government. Neither the United States Government nor any agency thereof, nor any of their employees, makes any warranty, express or implied, or assumes any legal liability or responsibility for the accuracy, completeness, or usefulness of any information, apparatus, product, or process disclosed, or represents that its use would not infringe privately owned rights. Reference herein to any specific commercial prajuct, process, or service by trade name, trademark, manufacturer, or otherwise does not necessarily constitute or imply its endorsement, recommendation, or favoring by the United States Government or any agency thereof. The views and opinions of authors expressed herein do not necessarily state or reflect those of the United States Government or any agency thereof.

\section{An Innovative Fuel Design Concept for \\ Improved Light Water Reactor \\ Performance and Safety: \\ Final Technical Report}

Award No. DE-F602-92ER75702

\author{
J.S. Tulenko, Principal Investigator \\ R.G. Connell, Co-Principal Investigator
}

\author{
Nuclear Engineering Sciences Department \\ Materials Science \& Engineering Department \\ College of Engineering \\ University of Florida \\ Gainesville, FL 32611
}

Reporting Period

$4 / 24 / 92-4 / 23 / 93$

Project Period

$4 / 24 / 92-4 / 23 / 93$

Program Manager:

Larry L. Barker

Project Co-Monitors:

T. Dolan

P. Lang 


\subsection{Overview}

The project "An Innovative Fuel Design Concept for Improved Light Water Reactor (LWR) Performance and Safety" is a three-year proiect to develop the basis for an improved fuel design which yields a safer and improved performance LWR fuel. The project is being conducted as an interdisciplinary project involving the Nuclear Engineering Sciences and Materials Science \& Engineering Departments. The student portion of the project is being carried out by a Ph.D. student in Nuclear Engineering, a master's degree student in Materials Science and undergraduate students in Nuclear Engineering. The students are assisted by three professors, two from Nuclear Engineering and one from Materials Science.

The design concept under development offers (1) reduced temperature operation and reduced stored heat, (2) reduced Doppler Effect and increased Doppler temperature coefficient at operating temperature, and (3) reduced fission gas release, fuel swelling and other improved fuel performance characteristics in addition to improved fuel transient response.

\section{$2.0 \quad$ Goals}

The primary goal of this research is to develop a new fuel design which will have improved thermal/mechanical performance characteristics greatly superior to current thermal and mechanical design performance. The mechanical/thermal constraints define the lifetime of the fuel, the maximum power at which the fuel can be operated, the probability of fuel failure over core lifetime, and the integrity of a core during a transient excursion. The thermal/mechanical limits act to degrade fuel integrity when they are violated. The purpose of this project is to investigate a novel design for light water reactor fuel which will extend fuel performance limits and improve reactor safety even further than is currently achieved. This project is investigating liquid metal bonding of LWR fuel in order to radically decrease fuel centerline temperatures which has major performance and safety benefits. The project will verify the compatibility of the liquid metal bond with both the fuel pellets and cladding material, verify the performance enhancement features of the new design over the fuel lifetime, and verify the economic fabricability of the concept and will show how this concept will benefit the LWR nuclear industry.

\subsection{Benefits and Relationship to Existing DOE Program}

The potential benefit of this project is the development of an improved light water reactor fuel which will lead to safe and more reliable nuclear power plant operation. Currently the 
Department of Energy is spearheading the development of Advanced Light Water Reactors which have as their basis the development of safer, more reliable, and more economical nuclear power plants.

The expected improved fuel performance can be a key ingredient to extending fuel burnup. Extending fuel burnup meets two key national goals of reducing high level radioactive waste disposal and increasing energy resources. Additionally, extending fuel burnup has a major effect on reducing energy costs.

4.0 Current Status of Tasks

The project is composed of five tasks. These five tasks are: 1) Material Compatibility, 2) Thermal-Hydraulic, Fuel Performance, and Safety, 3) Nuclear and Fuel Management Analysis, 4) Fuel Assessment (excore), and 5) Project Management.

During the reporting period major emphasis was focused on tasks $1,2,4$, and 5 . The progress obtained to date and future efforts are explained below.

\subsection{Material Compatibility Testing}

\subsubsection{Introduction}

The material compatibility of the liquid metal bond with the fuel and cladding must be demonstrated. The project has received a donation of Zircaloy cladding and natural enrichment uranium pellets from the Babcock and Wilcox Fuel Company which are being used in specially designed equipment to investigate the material compatibility of the proposed fuel design.

The two cases that are being closely examined are the interaction of the eutectic lead-bismuth with zircaloy-4 cladding under normal reactor operation conditions and also during a loss of coolant accident (LOCA). In order for lead-bismuth to be a liquid metal option as a heat transfer medium it must not corrode or embrittle the zircaloy cladding under the above cases.

Under normal reactor operation(SOP) the surface temperature of the zircaloy- 4 cladding is upper bounded by a value of $400^{\circ} \mathrm{C}\left(750^{\circ} \mathrm{F}\right)$. In addition, the zircaloy- 4 cladding must operate for thirty-forty thousand hours at SOP $\sim 3.9$ years of full power operation). Thus, it is necessary to examine the interactions between lead-bismuth and zircaloy cladding at temperatures in the normal operating range for times from one hundred to one thousand hours. From this examination, it will be possible to make predictions about lifetime applications. 
In a LOCA, the surface temperature of the zircaloy cladding will be bounded by temperatures on the order of $800^{\circ} \mathrm{C}\left(1472^{\circ} \mathrm{F}\right)$. However, the cladding will not remain at these elevated temperatures for more than 24 hours. Thus, high temperature, short time examinations of the leadbismuth and zircaloy interactions are necessary.

Liquid metals in contact with solid metals have the potential to interact by the following methods: simple solution, alloying, intergranular attack, temperature gradient mass transfer, and concentration gradient mass transfer (1). It is our goal to characterize the reaction/interaction between molten lead-bismuth and the zircaloy- 4 fuel cladding in order to deternine if any of the above mentioned methods of attack can occur.

\subsubsection{Experimental Procedure}

Since the goal is to characterize the interactions of lead-bismuth with zircaloy- 4 cladding it was necessary to design an experimental apparatus and procedure to test these materials under temperature conditions. Figure 1 shows testing apparatus which has been constructed for this project. The basic apparatus consists of the following:

1) Two Ther.nolyne tube furnaces

2) Two Omega Temperature controllers

3) Two vacuum pumps(rated $10-4$ torr)

4) Two Pirani vacuum gauges

5) Two union crosses

6) Six vacuum valves

7) Two type $K$ thermocouples

8) One dual temperature chart recorder

The temperature of the two tube furnaces is controlled by the external temperature controllers which are mounted on the instrument panel marked $\mathrm{A}$ in Figure 1. In addition, a valve panel attached to telescopic legs sits above each furnace. The valves on this panel open and close connections to the vacuum pumps and to a cylinder of helium which is used for backfilling after evacuation. The connections from the vacuum pumps to the valves have pirani gauges with digital displays hooked in-line. In addition to the valves, this panel also has a union cross attached to it which connects the valves and also allows for a specimen to be attached to the bottom port of the cross. Furthermore, this valve panel was designed to be lowered and raised by means of telescopic 
legs. This telescopic design is used for the ease of specimen loading and unloading. In order to monitor the temperature of the molten lead-bismuth, a special thermocouple port was designed on the valve panel that allows a thermocouple to be fed through the bottom port of the union cross directly into the melt.

Upon completion of the construction of the apparatus, it was then necessary to develop a testing procedure. Initially, it was decided that the testing procedure would consist of the following steps:

1) Allow furnace to come up to desired test temperature

2) Cut and weigh $\mathrm{Pb}-\mathrm{Bi}$ from $1 / 4$ " diameter wire stock

3) Place solid $\mathrm{Pb}-\mathrm{Bi}$ inside $\mathrm{Zr}-4$ tube with one end cap welded in place

4) Place open end of $\mathrm{Zr}-4$ tube into bottom port of union cross

5) Open vacuum valve allowing vacuum pump to evacuate inside of $\mathrm{Zr}-4$ tube

6) Once pirani gauge reads 15-20 mtorr, close vacuum valve, and open helium valve. Deliver helium at 2-4 psi

7) Close helium valve and re-open vacuum valve to re-evacuate $\mathrm{Zr}-4$ tube

8) Repeat backfill and purge process 3-4 times after final purge of helium, leave vacuum valve open and pumps running continuously

9) Set chart recorder scale and chart speed

10) Lower telescopic legs placing specimen in the furnace

11) Monitor chart recorder and adjust furnace temperature until melt thermocouple reads desired temperature

12) Allow specimen to run for allotted time then raise telescopic legs, allowing sample to cool in air under constant vacuum

For our initial experiments this system and procedure appeared to be satisfactory. However, after running some higher temperature specimens it became apparent that heating the $\mathrm{Zr}-4$ in air is not acceptable. Extensive oxidation of the outside surface occurred which interfered with our \% loss of wall thickness measurements. Thus, a slight modification of our original procedure was made. Instead of placing the $\mathrm{Zr}-4$ tubing directly into the bottom port of the union cross, the $\mathrm{Zr}-4$ tubing(with $\mathrm{Pb}-\mathrm{Bi}$ inside) is placed inside a 304 stainless steel sleeve which is then placed into the bottom port. The rest of the procedure remains the same except for the backfilling and purging(step 
8). After the final purging of helium instead of leaving the vacuum running continuously the vacuum is shut-off and the stainless steel sleeve is backfilled with helium at 2-4 psi. The sleeve remains filled with a positive pressure of helium during the entire run of the specimen. This constant positive pressure of helium has greatly minimized the external oxidation which make our $\%$ loss of wall thickness measurements more accurate and easier to measure.

Once the specimen has been run and allowed to cool to room temperature metallographic studies of the samples for \% loss of wall thickness and for type or nature of attack are performed. These studies involve taking a 1/4" section from the specimen and mounting in epoxy followed by polishing using standard metallographic techniques. These mounted specimens are the photographed using polaroid type 55 film on the LECO neophot. Measurements are taken from these pictures and compared to standard pictures which are made by taking $1 / 4$ " section from the $\mathrm{Zr}-4$ tube before it is tested. These comparison measurements provide us with accurare results for $\%$ loss of wall thickness. In addition to these \% loss studies polished samples are anodized using a solution of water,alcohol, phosphoric acid,lactic acid, and citric acid. The anodization procedure is done in an electrochemical cell using 12-24 volts for 30-45 seconds. Following this anodization procedure the samples are viewed under polarized light in the optical microscope in order to try and determine the method or cause of attack. Lastly, metallographic studies are done using the electron microprobe which allow us to take concentration readings on various regions of polished samples in hopes of determining the cause of the attack.

\subsubsection{Results and Future Work}

As of April 23, 1993, initial specimens have been run to simulate both the LOCA and SOP conditions. Test have been run for 24 hours at $650 \mathrm{C}, 750 \mathrm{C}, 825 \mathrm{C}$, and $900 \mathrm{C}$ to simulate the LOCA situation. Tests have also been run at $400 \mathrm{C}$ for 100 and 500 hours in order to simulate the SOP condition.

The percent loss of wall thickness measurements have shown some wastage at both temperatures but the results as yet are inconclusive. In addition, our initial metallographic examinations of these specimens shows that the attack appears to be uniform in nature which is better than anticipated. Initially, we had expected the attack to be intergranular in nature. Furthermore, one quite interesting result that has been found during our electron microprobe studies is that there seems to be a diffusion/transition layer developing between the lead-bismuth and the 
$\mathrm{Zr}-4$ tubing. Concentration profiles of this layer have shown it to be rich in bismuth. Additional work has been initiated to investigate the interactions of lead-tin and lead-tin-bismuth with the zircaloy-4 cladding.

The future work that has been planned is to perform four experiments simulating both the LOCA and SOP at different times and temperatures in order to develop a rate equation of \% wastage of wall thickness. Further metallographic studies will be completed especially concerning the transition layer which appears between the $\mathrm{Zr}-4$ and lead-bismuth. In addition, the application to begin material testing of the liquid metal and uranium dioxide and liquid metal, cladding, and uranium dioxide under temperature has been approved by the University Radioactive Safety committee. Additional tests will utilize lead-tin and lead-tin-bismuth in place of the lead-bismuth. The most satisfactory material will be investigated further.

Two testing procedures will be used in our experiment. The first apparatus will consist of placing a uranium-dioxide pellet in a small petri dish of molten $\mathrm{PbBi}$ eutectic to see if general wetting takes place. In addition, molten $\mathrm{PbBI}$ will be poured on top of the uranium dioxide pellet to ensure that the pellet is totally covered with $\mathrm{PbBi}$.

The second testing procedure is much more sophisticated and will require greater care. The second test consists of loading approximately 4-5 pellets into Zircaloy-4 fuel elements followed by placing a section of solidified $\mathrm{PbBi}$ on top of the pellets. This apparatus will then be placed into the bottom port of our testing apparatus and a vacuum will be pulled on the inside of the Zircaloy- 4 tubes. These tubes will then go through a process of backfilling with helium. This purging and backfilling procedure will be done approximately three times for each tube. Following this procedure, the tubes will be placed into our furnace and heated to the specified temperature for that experiment. This temperature range should be between 400-800 degrees celsius. The tubes wini remain in the furnace for a specified time (usually 24 hours) and then they will be removed and allowed to cool in air while still under vacuum. Once the samples are cooled metallographic techniques will be used to study the wetting and corrosive properties of the $\mathrm{PbBi}$ on the uraniumdioxide pellets.

The metallography of the tubing samples must be done with great care. In our study we want to make sure that we do not create airborne uranium-dioxide as we examine our samples. In order to ensure that no uranium-dioxide gets airborne, we will first section all samples using a 
LECO diamond saw that has a continuous flow of oil across the blade. This will ensure that no uranium-dioxide dust escapes. If there should be any problems with dust, this saw will be placed inside a contamination hood to further reduce any possibility of airborne uranium-dioxide. Once the samples are sectioned, they will be mounted in an epoxy-resin mounting compound. These mounted samples will then be ground and polished. The grinding and polishing operations will be done on a portable grinder/polisher which we are now in the process of obtaining. The entire grinding operation is done with a constant flow of water across the surface to keep dust from getting airborne. The polishing will be done under a water based polishing solution which will also keep uranium dust from getting airborne. In addition, since the grinding/polishing equipment is portable it can also be placed inside a contamination hood should any problems arise. Finally, once all testing has been completed all of the above mentioned equipment will be counted and then washed thoroughly with kerosene (which will be disposed of properly) and counted again. In addition, the grinding/polishing equipment will not be used again except by us for similar experiments.

\subsection{Thermal-Hydraulic, Fuel Performance, and Safety Analysis}

Thermal-mechanical analysis of the Liquid Bonded Light Water Reactor (LBLWR) reactor fuel was performed to determine: 1) the technical advantages of the fuel compared to conventional LWR fuel, 2) the fuel characteristics during normal operation and during postulated accidents, and 3) the thermal-mechanical performance of the fuel over a typical fuel cycle.

The technical merit of LBLWR fuel was demonstrated by performing thermal analysis on a typical fuel rod. To determine the operating characteristics of the fuel during nominal and accident conditions, a radial heat conduction model was constructed, and appropriate boundary conditions were applied to simulate reactor conditions. These analyses indicate that the advantage of the LBLWR fuel results from markedly lower fuel temperatures due to a significant decrease in the thermal impedance in the fuel gap. This improvement is achieved when the helium gas bond is replaced with a liquid metal bonding material in the gap which occurs between the fuel pellet and the zirconium cladding. This innovation results in lower fuel temperatures during normal operation, which improves fuel performance and reduces the risk of fuel damage during postulated accident conditions.

A computer code is being developed to determine the thermal-mechanical-material performance of the fuel over a typical fuel lifetime. This code is based on the ESCORE fuel 
performance code developed by the Electric Power Institute for light water reactors. The code is currently in the process of being modified to perform calculations for the LBLWR fuel.

\subsubsection{Thermal Analysis to Establish Technical Benefits}

The technical benefits of LBLWR fuel were enumerated in our proposal. The preliminary analyses performed to date show that fuel centerline temperatures are significantly lowered by replacing the fill gas (typically helium) in the space between the fuel pellet and the zirconium cladding, with a liquid metal (lead-bismuth eutectic). Material compatibility between the bonding material and the fuel pellet and cladding is being demonstrated in the current test program in task 1 .

\subsubsection{Steady-State Thermal Analysis}

Over the life of a conventional LWR fuel rod, the thermal conductance that occurs in the gas gap varies from 500 to $2000 \mathrm{Btu} / \mathrm{hr}-\mathrm{ft}^{2}-\mathrm{F}$. Liquid metal reactor fuel, which employs liquid metal bond material in the fuel-cladding gap, exhibits virtually zero thermal resistance across the gap.

A radial heat conduction model consisting of 20 fuel nodes, and 6 cladding nodes was constructed using the TRUMP generalized heat transfer computer program ${ }^{(2)}$. The effect of varying the thermal resistance between the fuel and cladding was studied by performing several steady-state calculations. The effect of varying the gap conductarice for a typical fuel rod (Westinghouse 17x17), is shown in Figure 3 for an average linear power of $6 \mathrm{~kW} / \mathrm{ft}$. Figure 4 shows the effect of varying gap conductance for a peak linear power of $13 \mathrm{~kW} / \mathrm{ft}$. These results show that the centerline fuel temperature for a LBLWR rod can be reduced from $150 \mathrm{~F}-650 \mathrm{~F}$ for an average power rod, and $450 \mathrm{~F}-1600 \mathrm{~F}$ for a peak power rod. Thus, a reduction of the fuel centerline temperatures translates directly into increased operating margins for LBLWR fuel, as compared to conventional LWR fuel.

Lower operating fuel temperatures also increases the fuel thermal conductivity, as is shown in Figure 5. Higher fuel thermal conductivity decreases the radial temperature gradient in the fuel pellet. The integrated effects of lower fuel temperatures and radial temperature gradient on operating fuel characteristics such as fission gas release, fuel cracking and swelling, fuel-cladding interaction, and clad integrity will be assessed using the fuel performance calculation code as modified by our project. 


\subsubsection{Transient Thermal Analysis}

The effect of reduced fuel centerline temperatures is significant from the standpoint of the transient thermal response during a postulated accident. The LBLWR fuel was evaluated for two accident scenarios; the loss of coolant, and the un-scrammed transient overpower. For both cases, the goal is to maintain the fuel rod integrity by assuring that the fuel doesn't melt, and that the peak cladding temperature remains lower than the threshold temperature for zirconium water reaction. The LBLWR fuel response will be compared to conventional LWR fuel for both postulated accidents.

The LBLWR fuel response to a loss of coolant accident (LOCA) was determined by assuming a normal operation, steady-state temperature profile, and then adjusting the heat transfer coefficient between the cladding and the coolant from forced convective cooling to a subcooled liquid $\left(6000 \mathrm{Btu} / \mathrm{hr}-\mathrm{ft}^{2}-\mathrm{F}\right)$, to steam cooling $\left(10 \mathrm{Btu} / \mathrm{hr}-\mathrm{ft}^{2}-\mathrm{F}\right)$. At the same time, the rod power is immediately reduced to decay heat levels due to the large negative void reactivity feedback.

Figure 6 shows the peak clad temperature for both fuel types assuming an initial peak rod power of $13 \mathrm{~kW} / \mathrm{ft}$. Due to the iarge reduction in heat transfer off the cladding surface, the fuel and cladding quickly reach an equilibrium temperature. The ultimate equilibrium temperature of the fuel and cladding depends on the peak fuel temperature, and the radial temperature gradient during steady-state operation. These results show that the peak clad temperature remains below $2000 \mathrm{~F}$ for LBLWR fuel as compared with $3000 \mathrm{~F}$ for conventional LWR fuel assuming a gap conductance of $500 \mathrm{Btu} / \mathrm{hr}-\mathrm{ft}^{2}-\mathrm{F}$.

The significance of lower cladding temperature during a postulated LOCA becomes apparent when comparing the peak clad temperatures against the temperature dependence for the zirconiumwater reaction ${ }^{(4)}$ as shown in Figure 7. The reaction rate increases exponentially with temperature, so by significantly reducing the peak clad temperature during a postulated accident, the risk of fuel failure due to zirconium-water reaction, and the associated severe accident concerns such as hydrogen generation is greatly reduced.

Lower operating fuel temperatures play a similar role in mitigating the effects of an unscrammed transient overpower event. For this case, the fuel rod is assurned to experience $15 \%$ step change in power at the start of the transient, and reach a new equilibrium temperature. For 
this simplified calculation, the effects of reactivity feedback from the increased fuel and moderator temperatures are not considered.

Figure 8 shows the centerline fuel temperature as a function of time for an LBLWR fuel rod and a conventional LWR fuel rod subjected to a $15 \%$ step increase in power. The rods are assumed to operate at $13 \mathrm{~kW} / \mathrm{ft}$ peak power before the transient, and the conventional fuel rod gap conductance is assumed to be $500 \mathrm{Btu} / \mathrm{hr}-\mathrm{ft}^{2}-\mathrm{F}$. The peak centerline fuel temperature is $5000 \mathrm{~F}$ for the conventional LWR fuel, which is well above the melting point of $\mathrm{UO}_{2}, 4500 \mathrm{~F}$. By comparison, the peak centerline fuel temperature for the LBLWR pin is $3200 \mathrm{~F}$.

The fuel transient response to a LOCA and to an unscrammed transient overpower event indicate that the LBLWR fuel is potentially far safer than conventional LWR fuel, and may preclude severe accidents involving fuel damage and hydrogen generation, even for peak power rods.

\subsubsection{Lifetime LBLWR Fuel Performance Calculations--The ESCORE Code}

To properly assess the thermal and mechanical behavior of fuel rods in a light water reactor, a computer code is being developed which accounts for the integrated effects of fuel and cladding deformation, cladding damage due to corrosion, fuel restructuring and fission gas evolution for an LBLWR fuel rod over a typical lifetime. The model is based on the ESCORE computer code which was originally developed by the Electric Power Research Institute to calculate the thermal and mechanical response of LWR fuel elements. The ESCORE code is replacing the LIFE code, which was originally planned to be modified for our work, because initial work indicated that modifications of a fast reactor fuel performance code to a light water reactor fuel performance code was impractical.

The ESCORE code was selected as the basis for an LBLWR fuel analysis code. The code includes a one-dimensional thermal model which is used to calculate the fuel and cladding temperatures as function of radial and axial position, and a one-dimension mechanical model to calculate fuel and cladding deformations and cladding damage. The fuel element is assumed to be axially symmetric, and is divided axially into several nodes. Each axial section is divided into cylindrical shells. The thermal and mechanical conditions of the fuel element are calculated incrementally as a function of time. The reactor operating conditions are averaged over each time step, and the behavior of the fuel element is calculated as a function of the reactor operating history. 
The thermal calculations are based on the assumption of steady-state radial heat transfer in the fuel and cladding. The axial temperature distribution in the coolant is calculated fron a specified inlet coolant condition, and the rod power. Thus, for every axial section, the radial temperature distribution is calculated from the local coolant temperature, local linear heat rate, cladding-coolant heat transfer coefficient, clad thermal conductivity, gap conductance, and fuel thermal conductivity. All material properties vary with temperature and are recalculated at each time step. The time steps are sufficiently short so that the thermal, fuel restructuring, fission gas release. and mechanical calculations are decoupled within the time step. Thus, once the temperature distribution is calculated for a time step, the incremental fuel restructuring, fission gas release, thermal expansion of the fuel and cladding, and plenum pressure are calculated.

The mechanical calculation is based on generalized plane strain and the method of successive elastic solutions. The plenum pressure, coolant pressure, and axial loads imposed by the core restraint system provide the boundary conditions. The incremental fuel and cladding deformation are calculated for every time step. Fuel deformation mechanisms include thermal expansion, elasticity, restructuring, creep, fission product swelling, hot pressing, and cracking. Cladding deformation mechanisms include thermal expansion, elasticity, creep, and irradiation-induced swelling. Fuel-cladding gap closure and total cladding strain are determined by a combination of all the deformation mechanisms. In addition, cladding damage due to chemical interaction with fission products and coolant is also calculated.

Several modifications have been identified to convert the ESCORE code to ESCORELBLWR, which will be used to analyze LBLWR fuel. These include:

1. change in the gap conductance calculation to reflect liquid metal bond material

2. modification of the thermal hydraulic mode to calculate the pellet-liquid bondto-clad heat transfer coefficient

In addition, material properties are being included for various liquid bond materials.

The final modification, the gap conductance model, will be upgraded to include liquid metal bonding. The code will then be used to predict the fuel lifetime performance parameters for LBLWR fuel. 


\subsubsection{Fission Gas Release}

The design of fuel rods must address fission gas evolution and release from fuel which occurs as a function of burnup and fuel operating temperature. Fission gases released from conventional fuel rods affect the gas gap conductance, internal rod pressure, fuel pellet swelling and cracking, and fuel/cladding interaction. The fuel design must assure that the mechanical loads imparted to the cladding as a resilt of the release of fission gas do not stress the cladding and give rise to conditions that would fail the fuel rod.

For liquid metal bonded fuel, transport of fission gas away from the surface of the fuel to a gas plenum to assure the thermal integrity of the liquid bond is of primary importance to maintain fuel operating temperatures. Liquid metal reactors which utilize a liquid metal bonded fuel design incorporate a gas plenum at the top of the fuel rod. Successful operation of this fuel indicates that the transport of the fission gas from the surface of the fuel pellets to the gas plenum occurs during the life of the fuel, and that the thermal bond between the fuel and cladding is not degraded. Argonne National Laboratory has run tests to confirin that fission gas bubbles do not become entailed in the liquid sodium, but travel up the length of the fuel rod to the fission gas plenum area.

The evolution of fission gas is a statistical process which occurs as the uranium atoms undergo fission. Thus, fission gas evolution is solely a function of the fuel burnup, and will be the same for LMBLWR fuel as for conventional LWR fuel. The evolved gases are contained within the structure of the fuel pellet, and are not immediately released from the fuel. The release of fission gas from the fuel is dominated by diffusion of the gas through the lattice structure, and follows a well known rate equation for diffusion of a gas through a solid (Reference 5 ). The amount of gas released (moles/cc-hr) in a given time period is

$$
\Delta R_{j}=K_{1} P_{j} \Delta t_{j}+\frac{K_{2}}{3}\left[\left(\sum_{i=1}^{j} P_{j} \Delta t_{j}\right)^{3}-\left(\sum_{i-1}^{j-1} P_{j} \Delta t_{j}\right)^{3}\right]
$$

where $\Delta R_{j} \quad$ is the amount of gas released during time step $j$

$\Delta \mathrm{t}_{\mathrm{j}} \quad$ is the length of time step $\mathrm{j}(\mathrm{hr})$

$\mathrm{P} \quad$ is the gas production rate (moles/cc-hr)

and $\mathrm{K}_{1}$ and $\mathrm{K}_{2}$ are Arrhenius type functions of temperature and are expressed as 


$$
\begin{aligned}
& \mathrm{K}_{1}=\mathrm{A}_{1} \exp \left[-\mathrm{B}_{1} / \mathrm{T}_{1}\right] \\
& \mathrm{K}_{2}=\mathrm{A}_{2} \exp \left[-\mathrm{B}_{1} / \mathrm{T}_{1}\right]
\end{aligned}
$$

where $T_{1}$ is the local fuel absolute temperature and $A_{1}, B_{1}, A_{2}$, and $B_{2}$ are constant defined in Reference 6 as:

$$
\begin{aligned}
& \mathrm{A}_{1}=388264 . \\
& \mathrm{B}_{1}=44554 .{ }^{\circ} \mathrm{R} \\
& \mathrm{A}_{2}=5.787 \mathrm{E} 9 \\
& \mathrm{~B}_{2}=15250 .{ }^{\circ} \mathrm{R}
\end{aligned}
$$

Figure 9 shows the relationship of fission gas release with fuel temperature as described by this model. Because the gas is interred inside the pellet, lower gas release is expected over the life of the LMBLWR fuel rod, as compared to conventional fuel. However, at high burnup $(\sim 160,000$ $\mathrm{MWd} / \mathrm{MT}$ ), it is expected that the fission gas will be released quickly due to depletion of the fuel lattice structure close to the surface of the fuel pellet.

\subsection{Nuclear and Fuel Management Analysis}

Work in this area is addressing the neutronic effects of the reduced fuel temperature operation of the liquid metal bonded fuel. During the reporting period, the nuclear fuel cycle cost code EPCOST was obtained from Oak Ridge and preliminary cycle cost runs were made. In addition LEOPARD runs were made to confirm the increase in the Doppler coefficient of $26 \%$ and to initiate the generation of constants for a fuel management study. Dr. Dalton will lead this effort in the second year of the program.

\subsection{Fuel Assessment}

The Fuel Assessment Task is addressing all excore (out of core) areas including manufacturing, handling, and fuel disposal. The Babcock and Wilcox donation included fuel rod end caps and internal rod components such as upper and lower fuel rod springs. As soon as the Radiation Control Committee clears the use of the natural uranium pellets, the loading of the lead bismuth liquid bond will be tested to review fabrication procedures.

In the absence of a release on the $\mathrm{UO}_{2}$ pellets, $\mathrm{Al}_{2} \mathrm{O}_{3}$ pellets were used with the $\mathrm{Zr}-4$ (17x17 size tubing) to determine if the $\mathrm{PbBi}$ could be loaded and would fill the gap between the pellets and the clad. Runs were made at $392-592^{\circ} \mathrm{F}\left(175-255^{\circ} \mathrm{C}\right)$. The pellets provided a gap of 0.005 inches on the diameter. The experiments were successful. Examination conducted by sectioning the tube 
and pellets showed the gap to be completely filled. Three test runs were made with each test showing very similar results. The $\mathrm{PbBi}$ eutectic filled the 5 mil gap with the filling uniform and around the entire circumference of the $\mathrm{Al}_{2} \mathrm{O}_{3}$ pellet.

\subsection{Project Management}

The project is composed of an interdisciplinary team of professors and students from the Nuclear Engineering Sciences Department and the Materials Science \& Engineering Department. In order to coordinate technical activities, a weekly meeting is held every Monday at 9:00 a.m. to review results of the past weeks activities and plan the coming week's research. These meetings have helped to ensure that research activities are taking place in a timely manner in accordance with project schedules.

At this point, the project is on schedule or slightly ahead. Equipment procurement and laboratory experimental setup has gone very smoothly. The Babcock \& Wilcox donations have been a major boon to the project and the receipt of the fuel cycle code from Oak Ridge occurred in a timely manner.

Experimental results to date have been conducted on schedule with no major problems encountered. The program is following the three year schedule originally projected. No money will be carried over into year two. The original proposal is still the governing document for the program.

\subsection{3-1994 Project Activities}

The project is on schedule and is $\mathrm{f}$ inding activities in accordance with the original proposal. Activities for the 1993-1994 period are as originally proposed and are reviewed below.

\subsection{Material Compatibility}

The material compatibility testing will continue with the focus of the research investigating the $\mathrm{Zr}-4$ tubing with $\mathrm{UO}_{2}$ pellets and $\mathrm{PbBi}$ bonding. These tests will indicate whether there are any reactions driven by the synergy of the three materials.

\subsection{Thermal-Hydraulic, Fuel Performance and Safety Analysis}

This task will continue on with activities undertaken in the first year. The principle activity will be the modification of a fuel performance code to enable a comparison of the thermal-hydraulic 
and fuel performance characteristics as a function of burnup. With these values safety analysis will be extended to the end of life performance.

Work will commence to construct and operate apparatus to test a hot $\mathrm{PbBi}$ bonded fuel rod with $\mathrm{Zr}-4$ clad and $\mathrm{Al}_{2} \mathrm{O}_{3}$ pellets which is intentional defected. The test will define behavior of defected fuel assemblies.

\subsection{Nuclear and Fuel Management Analysis}

Work will continue on analyzing the fuel nuclear performance using the LEOPARD code to generate cross sections and the EASYCYCLE code to review power peaking and core performance calculations. The economic benefits will be calculated with the EPCOST code.

\section{$5.4 \quad$ Fuel Assessment}

The fabricability of the liquid bonded fuel will be confirmed utilizing $\mathrm{UO}_{2}$ pellets in the $\mathrm{Zr}-4$ tubing. Testing with the $\mathrm{Al}_{2} \mathrm{O}_{3}$ pellets will also continue because of radiactive waste considerations.

\subsection{Project Management}

The project management of the project will continue with Ms. K. Phillips acting as Administrator. The project will hold weekly meetings on Monday morning at 9:00 a.m. To review past activities and plan future work. It is expected that three (3) papers will be published on results attained to date during 1993-1994. 


\section{$\underline{\text { References }}$}

1. W.D. Manly, "Fundamentals of Liquid Metal Corrosion", Corrosion, 12, 46-52, 1956.

2. J. Rest, "SST: A Computer Code to Predict Fuel Response and Fission Product Release from Light Water Reactor Fuels During Steady-State and Transient Conditions," Trans. Am. Nucl. Soc. 22(1), 462-463, November 1975.

3. M.G. Andrews, H.R. Freeburn, and S.R. Pati, "Light Water Reactor Fuel Rod Modeling Code Evaluation, Phase II Topical Report", CENPD-218, Combustion Engineering, Inc., Appendix A, April 1976.

4. P.E. MacDonald, ed., "MATPRO: A Handbook of Materials Properties for Use in the Analysis of Light Water Reactor Fuel Rod Behavior", ANCR-1263, NRC-5, Aerojet Nuclear Company, February 1976.

5. PA-115-75, "Derivation of a Burnup Dependent Fission Gas Release Model for Use in the PAD Fuel Performance Code", Westinghouse, August 1975.

6. PA-123-75, "Comparison of PAD 3.3 Predicted and Measured Data on Fission Gas Release Fuel Density", Westinghouse Internal document, August 1975. 


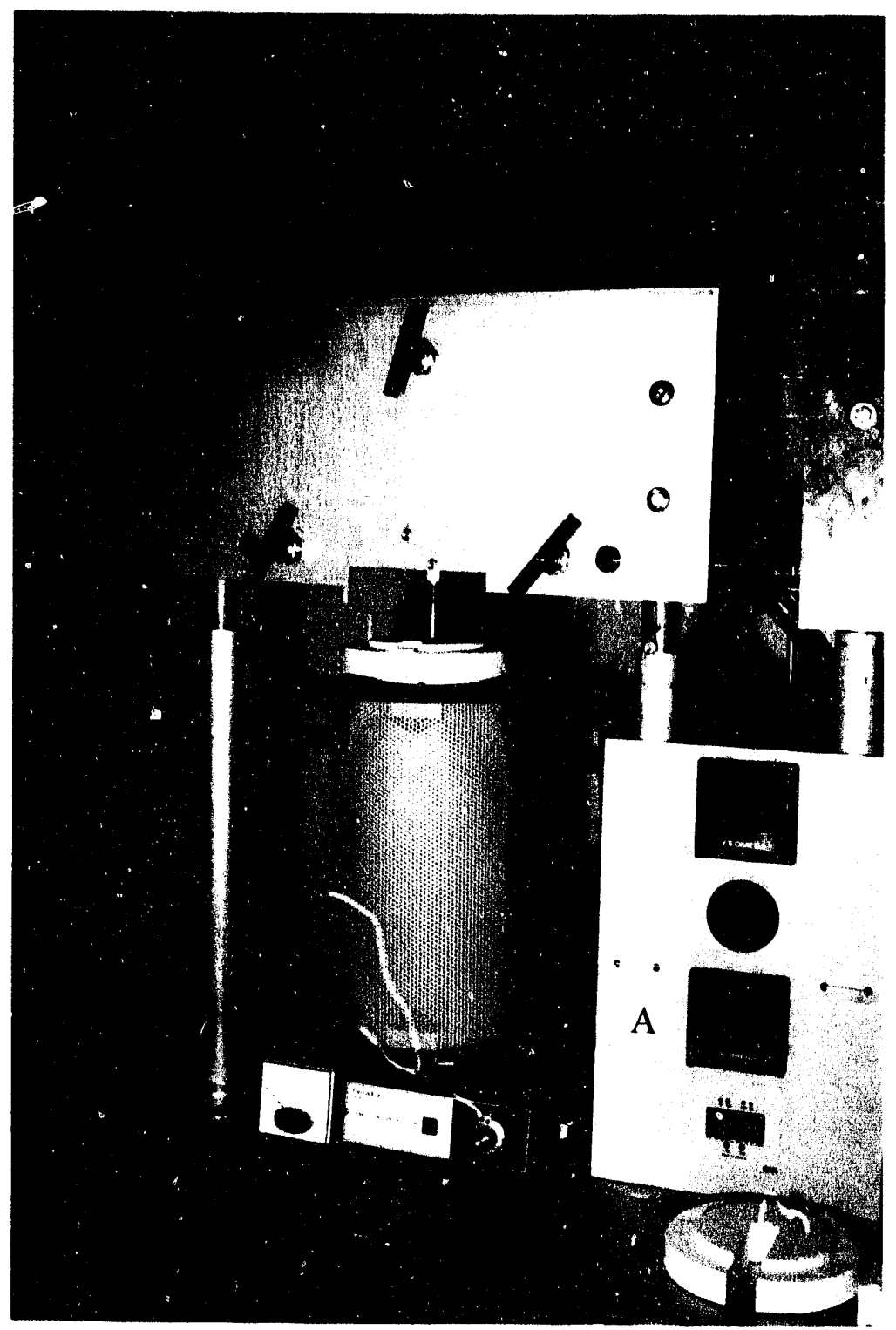

Figure 1: Testing apparatus showing tube furnace valves and control panel

Control panel marked A 


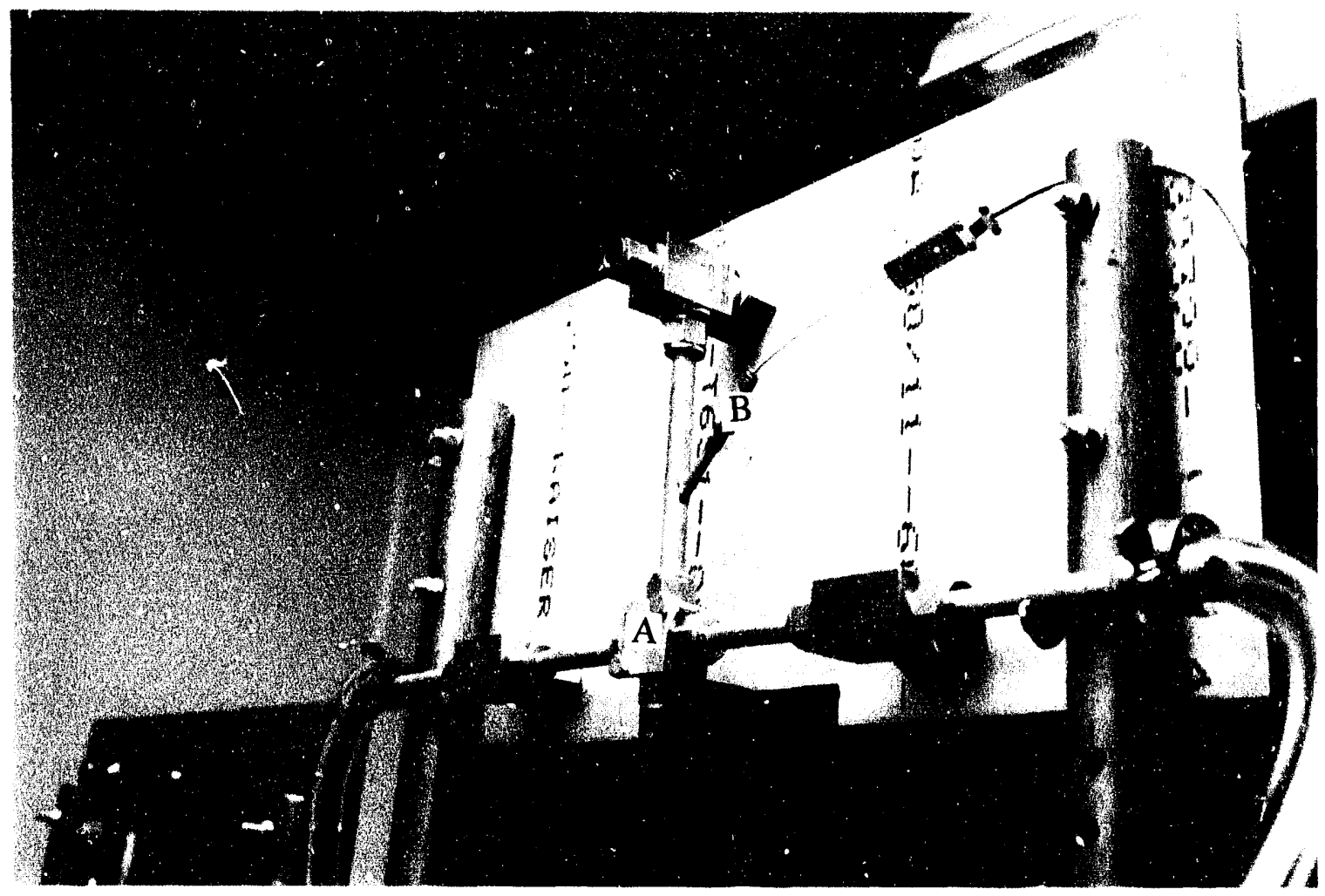

Figure 2: Testing apparatus showing union cross, thermocouple port and valve connections

Union Cross

marked A
Thermocouple port marked B 


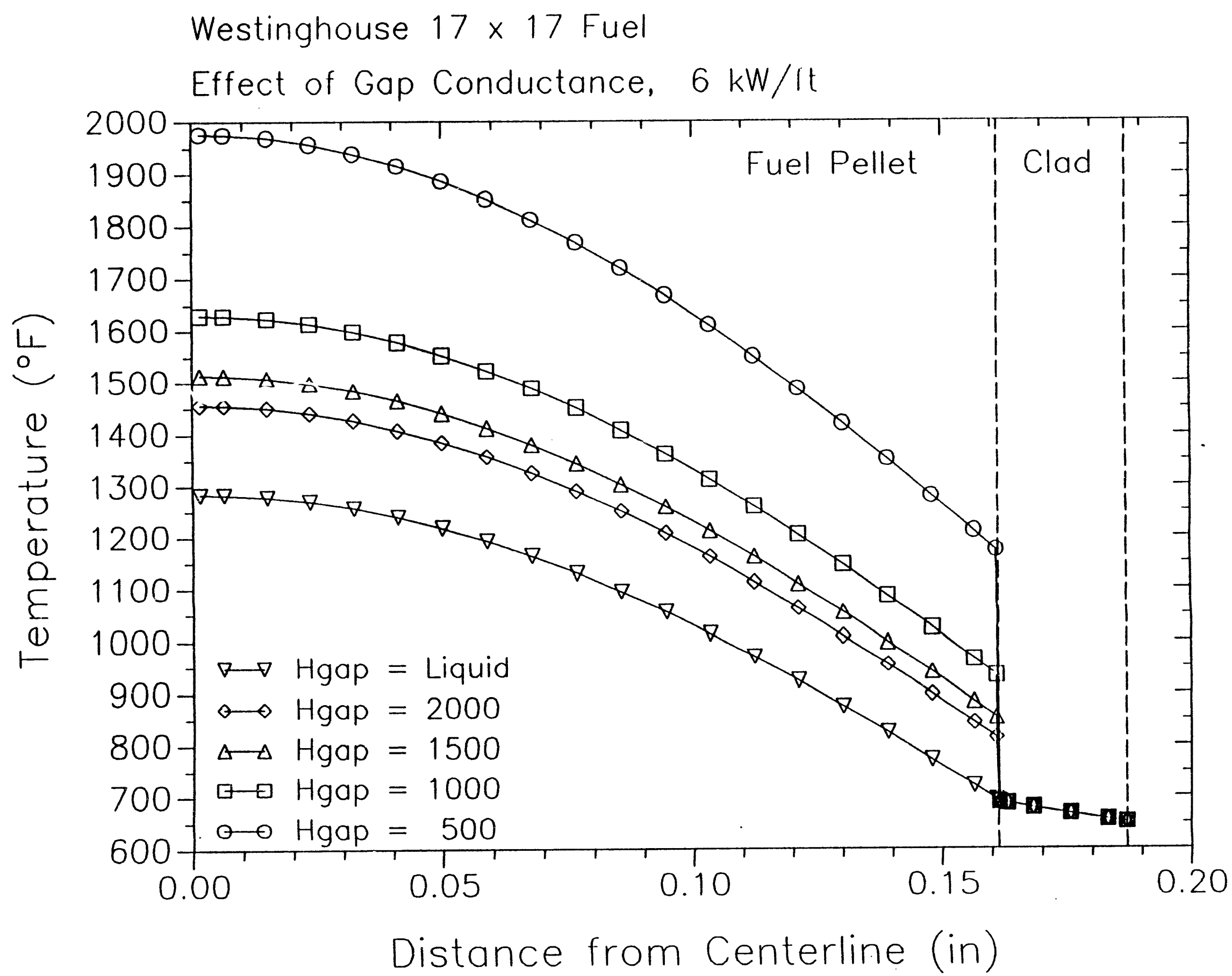




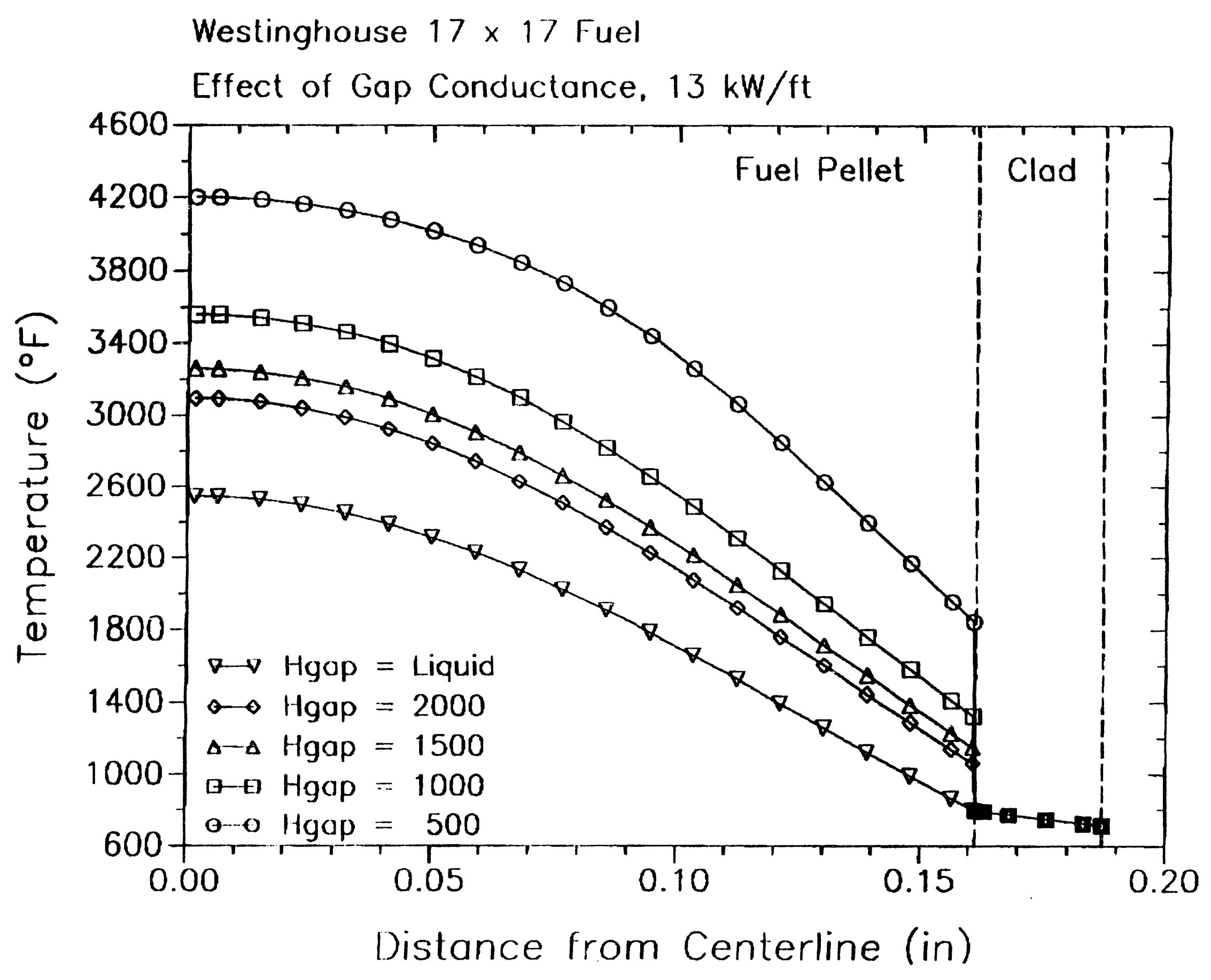


Fuel Thermal Conductivity vs. Temperature

LBLWR vs. Conventional Fuel

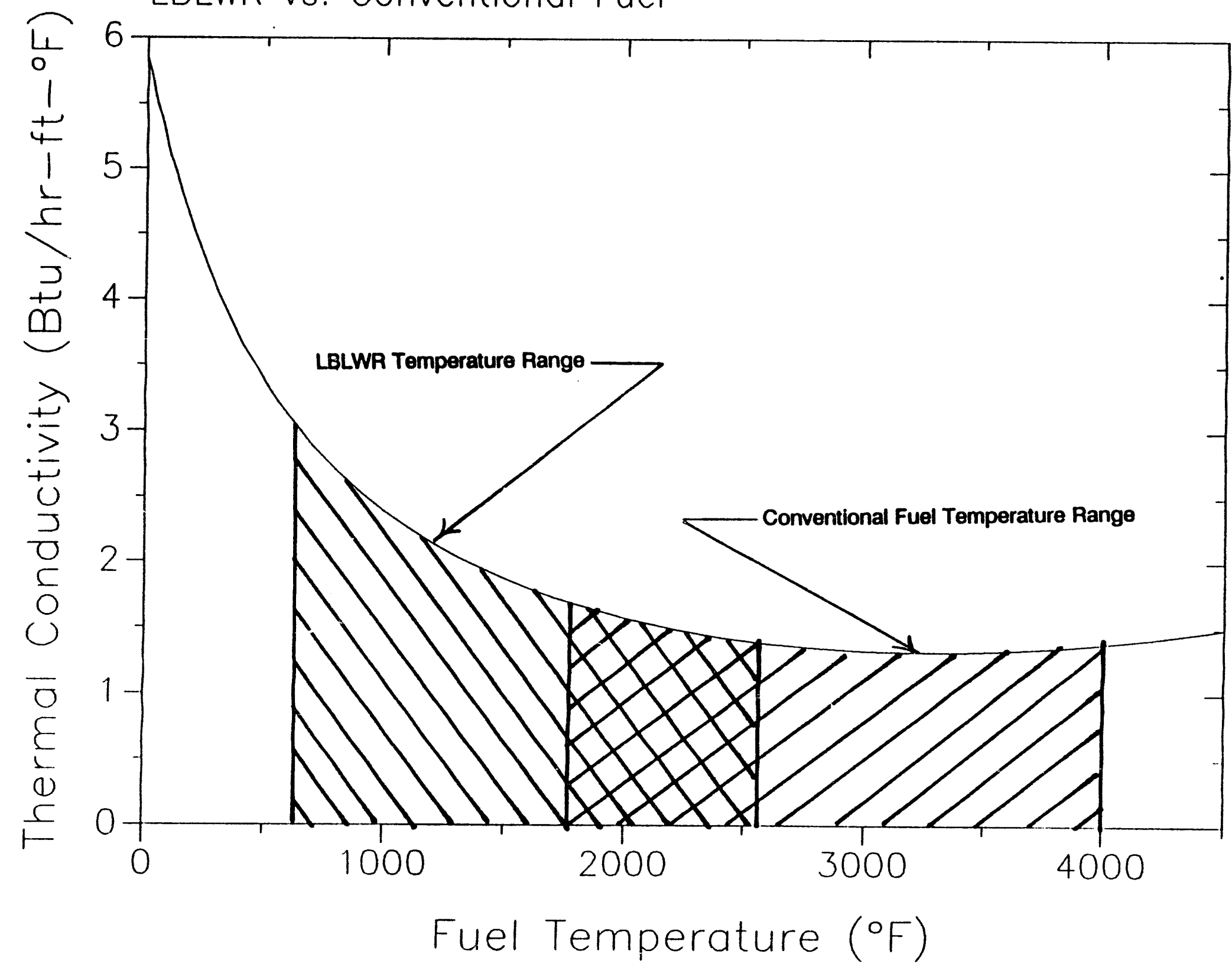

Figure 5 Effect of Operating Temperature Range on Fuel Thermal Conductivity 


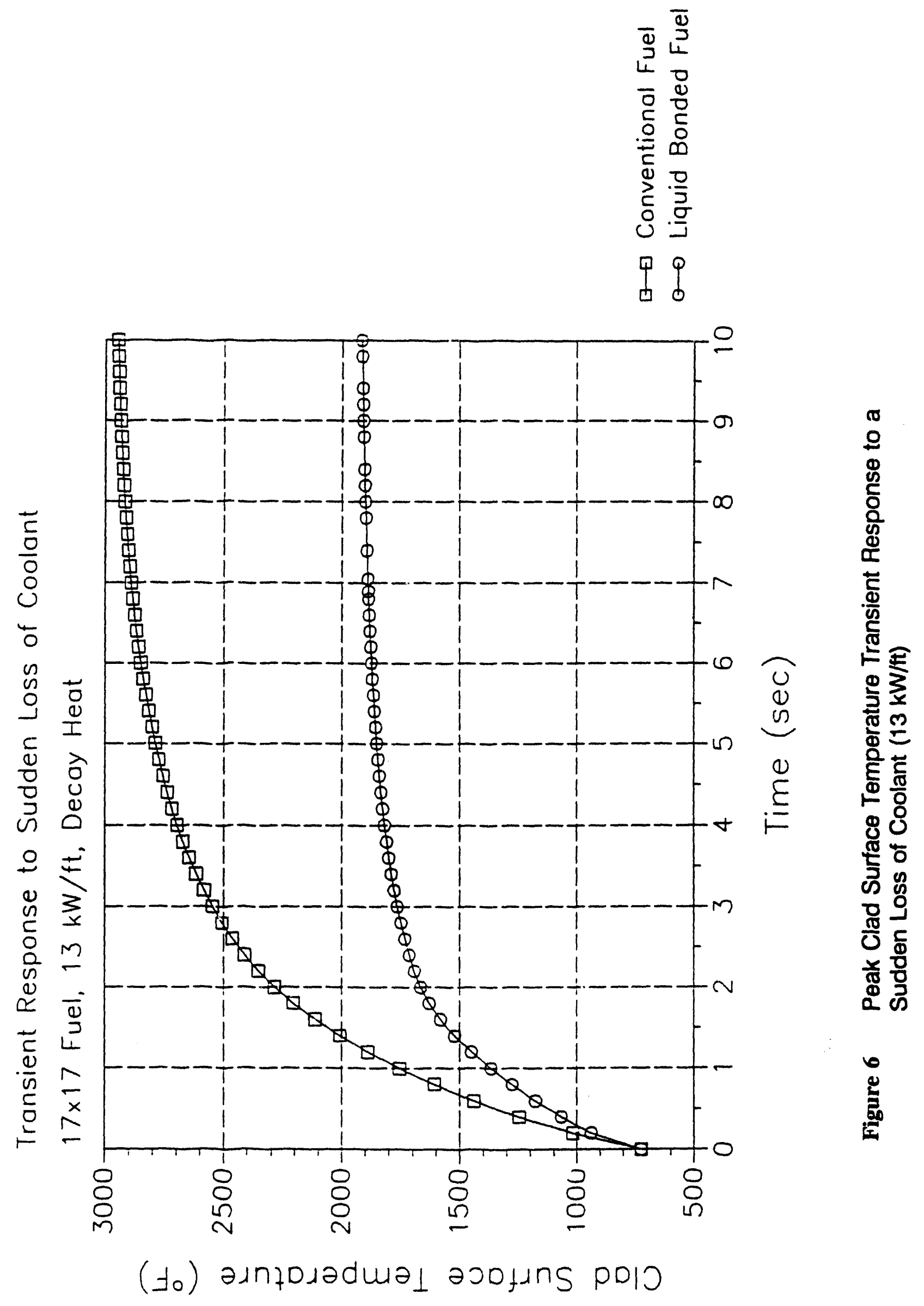


Zirconium-Water Parabolic Rate Constant vs. Temp.

Baker-Just Correlation

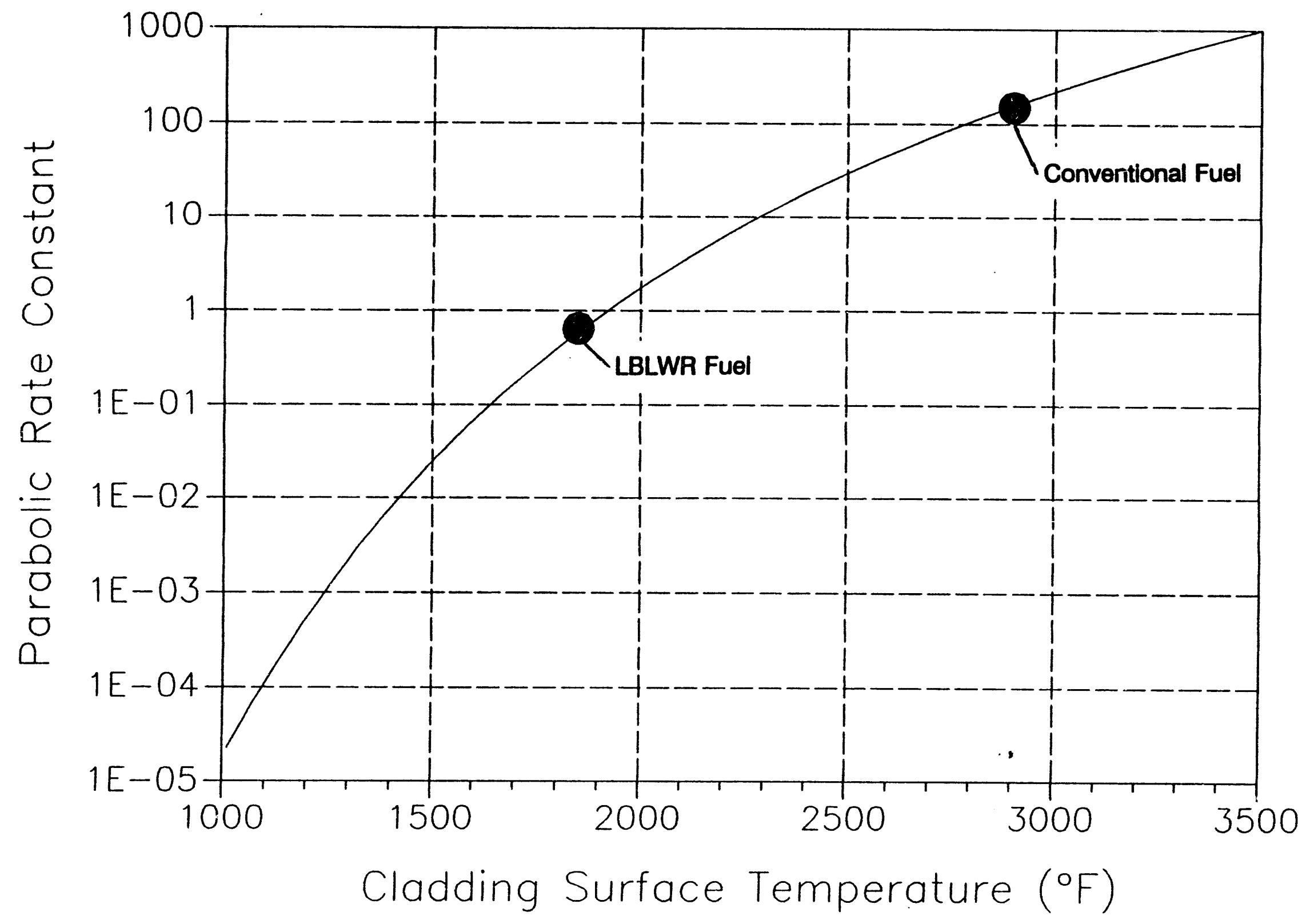

Figure 7 Peak Clad Temperatures During LOCA, and the Effect on $\mathrm{Zr}-\mathrm{H}_{2} \mathrm{O}$ Reaction Rate 
Transient Response to $20 \%$ Overpower

$17 \times 17$ Fuel, $13 \mathrm{~kW} / \mathrm{ft}$

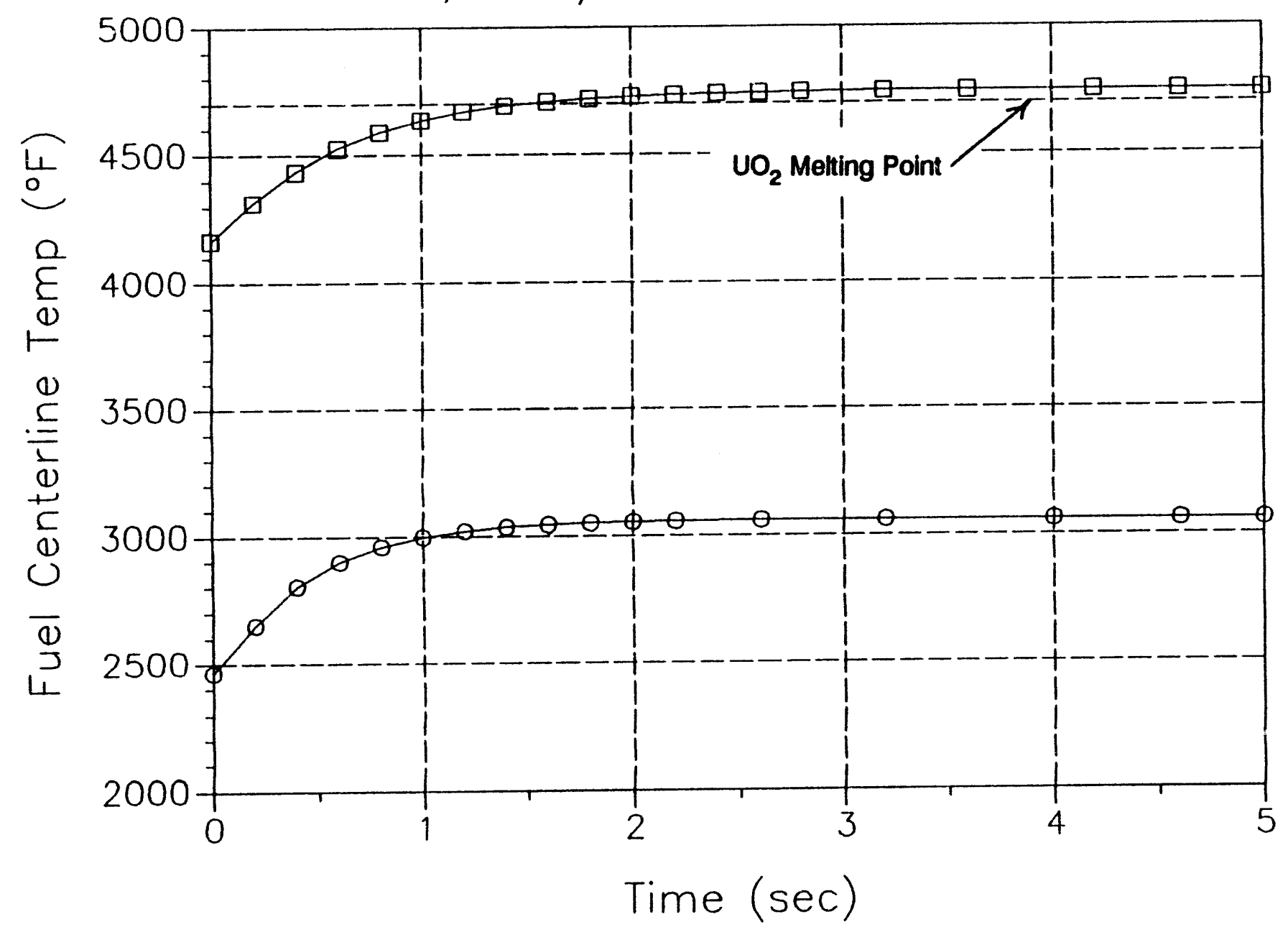

$\square-$ Conventional Fuel $\multimap$ Liquid Bonded Fuel

Figure 8 : Fuel Transient Response to 20\% Overpower 


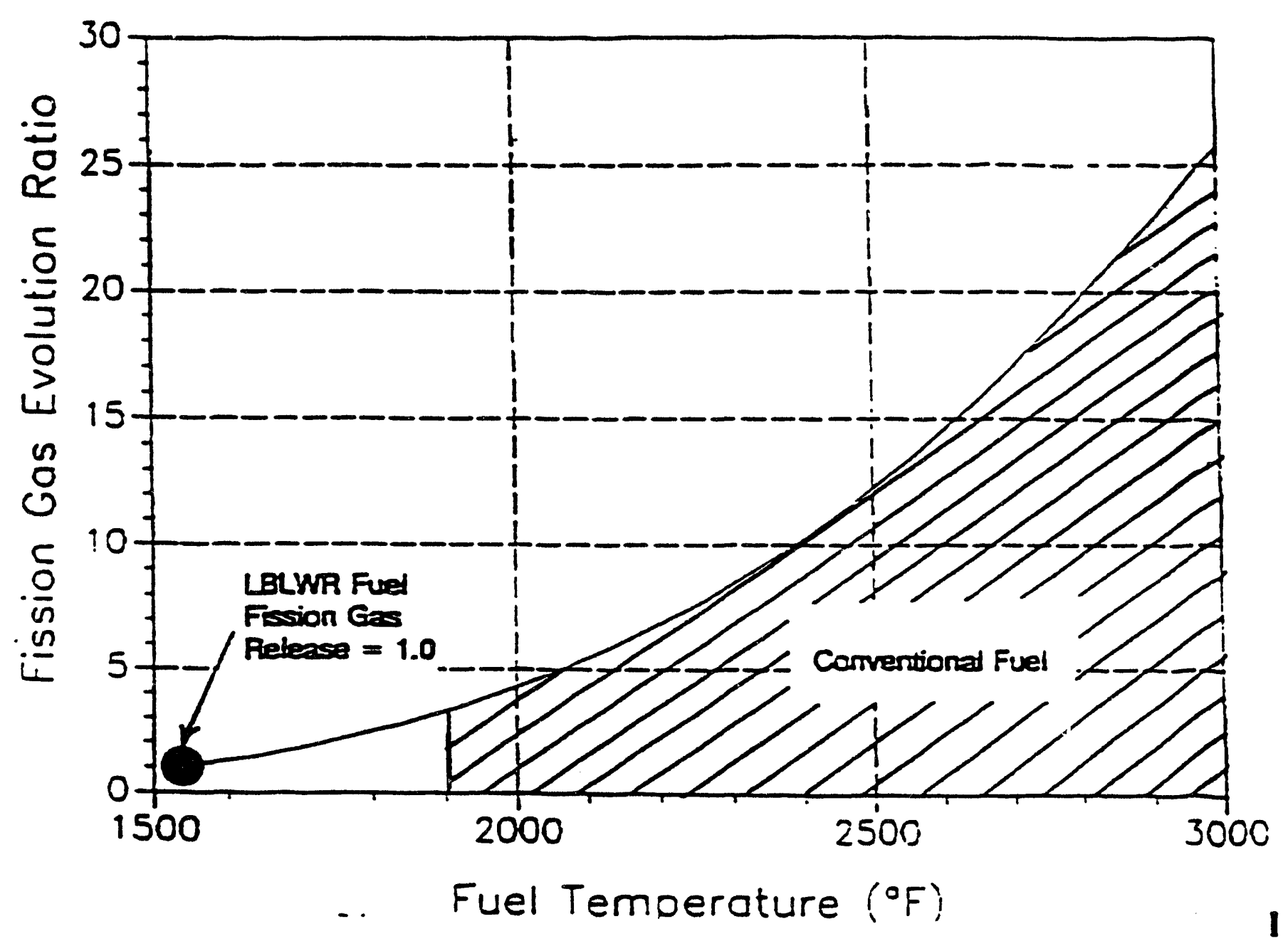

Figure 9 - Fission Gas Release vs. Fuel Temperature

Ratio based on LBLWR Fuel with $T_{m z}=1530^{\circ} \mathrm{F}$ 


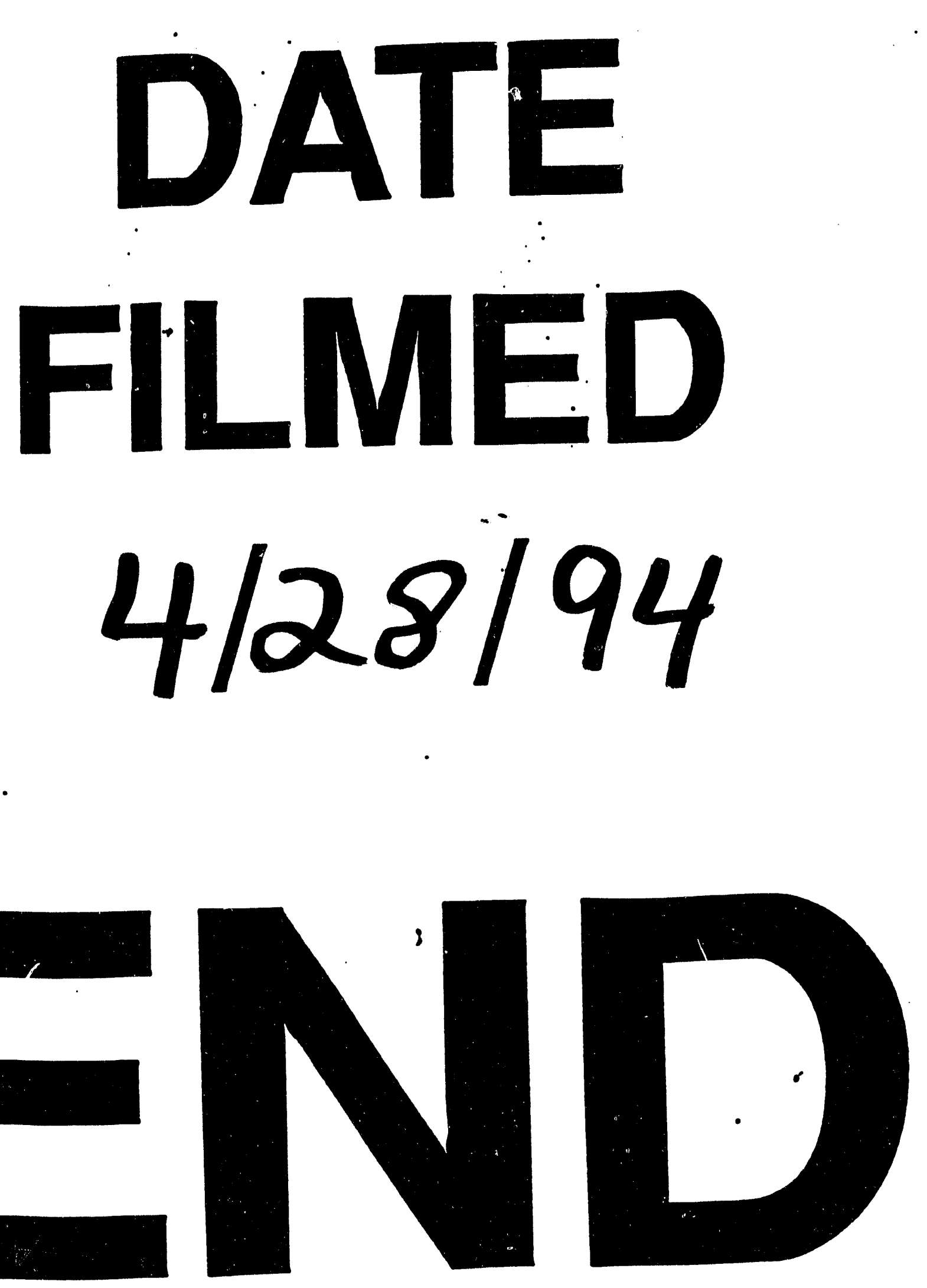


